\title{
Thermographic differences due to dynamic work tasks on individuals with different obesity levels: a preliminary study
}

\author{
Ana Colim, Pedro Arezes, Paulo Flores, Ricardo Vardasca and Ana Cristina Braga
}

\begin{abstract}
QUERY SHEET
This page lists questions we have about your paper. The numbers displayed at left are hyperlinked to the location of the query in your paper.

The title and author names are listed on this sheet as they will be published, both on your paper and on the Table of Contents. Please review and ensure the information is correct and advise us if any changes need to be made. In addition, please review your paper as a whole for typographical and essential corrections.

Your PDF proof has been enabled so that you can comment on the proof directly using Adobe Acrobat. For further information on marking corrections using Acrobat, please visit http://journalauthors.tandf.co.uk/production/acrobat.asp; https://authorservices.taylorandfrancis.com/how-to-correct-proofs-with-adobe/

The CrossRef database (www.crossref.org/) has been used to validate the references. Changes resulting from mismatches are tracked in red font.
\end{abstract}

\section{AUTHOR QUERIES}

Q1 Please note that the ORCID for Ana Colim has been created from information provided through CATS. Please correct if this is inaccurate.

Q2 Please note that the ORCID for Pedro Arezes has been created from information provided through CATS. Please correct if this is inaccurate.

Q3 Please note that the ORCID for Paulo Flores has been created from information provided through CATS. Please correct if this is inaccurate.

Q4 Please note that the ORCID for Ana Cristina Braga has been created from information provided through CATS. Please correct if this is inaccurate.

Q5 Please check author names (givenname: Ana in CATS)

Q6 Please check whether the word "Program" is used in the computing context; if not, please change it to "programme" here and in subsequent instances if any.

Q7 Please check whether the word "program" is used in the computing context; if not, please change it to "programme" here and in subsequent instances if any.

Q8 Please check whether the word "programs" is used in the computing context; if not, please change it to "programmes" here and in subsequent instances if any.

Q9 The abstract is currently too long. Please edit the abstract down to no more than 200 words.

Q10 The funding information provided has been checked against the Open Funder Registry and we failed to find a match. Please confirm if the Funding section is accurate and also confirm the funder names.

Q11 The PubMed (http://www.ncbi.nlm.nih.gov/pubmed) and CrossRef (www.crossref.org/) databases have been used to validate the references. Mismatches between the original manuscript and PubMed or CrossRef are tracked in red font. Please provide a revision if the change is incorrect. Do not comment on correct changes.

Q12 Please provide missing page number for the "Antwi-Afari et al., 2018" references list entry.

Q13 Please provide missing volume number for the "Park et al., 2009" references list entry.

Q14 Please provide missing Publisher location for the "Saunders et al., 2007" references list entry. 


\title{
Thermographic differences due to dynamic work tasks on individuals with different obesity levels: a preliminary study
}

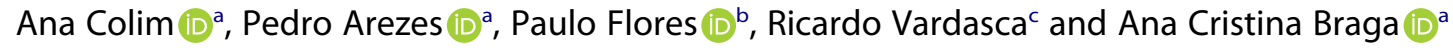 \\ ${ }^{a}$ ALGORITMI Centre, University of Minho, Guimarães, Portugal; 'bCMEMS, University of Minho, Guimarães, Portugal; ' $\mathrm{c}$ INEGI-LAETA, University of Porto, \\ Porto, Portugal
}

\section{ABSTRACT}

Obesity has been identified as a potential risk factor for Work-Related Musculoskeletal Disorders (WRMSD). However, literature shows that more studies are required about obesity effects on work performance, including during lifting tasks. Infrared Thermography (IRT) has been emerged as an alternative technique to study WRMSD risk factors. Therefore, the current study aims at testing whether skin temperatures $\left(T_{\text {skin }}\right)$ changes are sensitive to work conditions during lifting tasks. The second goal of this work is to analyse possible differences in $\mathrm{T}_{\text {skin }}$ changes across individuals with different obesity levels. By applying IRT imaging this study considered 29 participants with different obesity levels, for a repetitive lifting task between floor and shoulders height with a periodicity of 7 seconds up to 2 minutes. Thermal images were registered across 16 Regions Of Interest (ROI) (divided into body anterior and posterior views). Data analysis was performed from the temperatures differential, calculated as the algebric difference between $T_{\text {skin }}$ measured before and after the task. This $T_{\text {skin }}$ difference presented statistical evidence ( $p<0.05$ for all ROI), with a decrease after the task. The average $T_{\text {skin }}$ decrease of the $8 \mathrm{ROI}$ for anterior view was $0.33( \pm 0.08)^{\circ} \mathrm{C}$ and for posterior view was $0.51( \pm 0.08)^{\circ} \mathrm{C}$, being an indicator of muscular overload increased. Results show a relation between the obese participants and the presence of higher cooling in the ROI studied, following the lifting task. These outcomes corroborate that obesity is a WRMSD risk factor and also provides evidence that IRT can be a useful tool to assess the participants' biomechanics performance.
ARTICLE HISTORY

Received 25 March 2019

Accepted 22 November 2019

\section{KEYWORDS}

Thermography; ROl; skin temperature; biomechanical overload; obesity; lifting task

\section{Introduction}

\section{obesity}

Over the last decades, obesity has been recognised as a relevant health problem of industrialised countries (Nigatu et al. 2016; Gu et al. 2016). From the worldwide statistics, it can be observed that obesity has more than doubled since 1980 (World Health Organization - WHO 2016). Obese workers represent a growing fraction in the workforce, however, obesity is often associated with different conditions and contexts, such as Work-Related Musculoskeletal Disorders (WRMSD), which even-

35 tually can decrease workers' productivity (Lidstone et al. 2006; Morris 2007; Gates et al. 2008). Different studies have shown a correlation between obesity and an increase in absenteeism related to WRMSD (Tsai et al. 2008; Lier et al. 2009). Lin et al. (2013), when analysing statistical data over 12 years of the USA population, found that obesity associated with a WRMSD risk increased about $25 \%$. The association between obesity and different musculoskeletal problems is well documented by several research works, e.g.: rheumatism, osteoarthritis (Lidstone et al. 2006; WHO 2016), tendinitis in the upper limbs (being the probability of occurrence two times superior in obese workers, compared with non-obese) (Werner et al. 2005), carpal tunnel syndrome (with a probability of occurrence augmented four times in obese workers) (Kurt et al. 2008). Back pain is also an occupational health problem, which is more severe in obese workers (Shariat et al. 2018).

Several findings have also correlated obesity to impairments on muscle capacity, namely: lower muscle strength relative to the body mass (Hulens et al. 2001; Cavuoto and Nussbaum 2013); and lower resistance to muscle fatigue (Maffiuletti et al. 2007; Cavuoto and Nussbaum 2014). Concerning the WRMSD, it has been established that workers who perform manual handling loads are exposed to a greater risk of developing WRMSD (Umer et al. 2016; Antwi-Afari et al. 2018) when compared to those with jobs that do not require this kind of activities (Mital et al. 1997). However, repetitive manual tasks, such as lifting and lowering loads, are very common in a wide variety of industrial workplaces and are associated with several occupational and individual WRMSD risk factors (Yeung et al. 2002; Arezes et al. 2011; Antwi-Afari et al. 2017). One of these individual risk factors is workers' body composition, including their level of obesity (Marras 2000; Colim et al. 2019; Corbeil et al. 2019). For instance, Corbeil et al. (2019) studied the task dealing with moving boxes from a conveyor to a hand trolley and back, with 17 obese and 20 non-obese handlers. In their investigation, with the purpose to develop a biomechanical model, which estimates net moments at L5-S1, kinematic and kinetic data were collected and analysed The authors evidenced that the excess weight of obese workers has a significant added effect on the musculoskeletal structures of the back, exposing these workers to a higher 
75 risk of developing a WRMSD during load handling. However, most of the observational methods proposed, based on biomechanics' criteria, and used in WRMSD risk assessment and ergonomic assessment of workplaces and tasks do not consider the workers' body composition as a risk factor (Park et al. 2009).

The Body Fat Mass (BFM), Abdominal Circumference (AC) and Body Mass Index (BMI) measurement have been widely used in the assessment of obesity and to quantify the risk of obesity-related disorders (Paniagua et al. 2008). It should be noted that in the majority of previous mentioned studies about the effects of obesity on work performance, BMI has been the principal indicator utilised for sample characterisation. Nevertheless, BMI has limitations, since it is only based on the subject's weight and height. The evaluation of this indicator does not consider any distinction between body fat-free mass

90 and fat mass, as it does not characterise body fat mass distribution (Akpinar et al. 2007). Therefore, its specificity and predictive ability in the identification of health problems associated with obesity have been questioned (Singh et al. 2009). In fact, $\mathrm{BMI}$ is considered to be a fallible measure for a detailed assessment of body composition and should not be used to classify the individual level of obesity (Beechy et al. 2012), demanding the use more appropriate and comprehensive obesity assessment techniques. For these reasons, in this study obesity levels were categorised, according to subjects' AC and BFM, determined by Bioelectrical Impedance Analysis (BIA). BIA allows for the quantification of body impedance by applying electrodes connected to different body regions, in order to create a circuit through which the innocuous current can pass. As the different human tissues exhibit different resistances to the passage of electric current, BIA devices determine the amount of/ean body mass and body water as well as fat (Kyle et al. 2004; Beechy et al. 2012). These measures are obtained by using analytical expressions that are adjusted to individual factors such as age, gender, height, and weight. This analytical approach (which vary according to the equipment used) must be validated for the population in question, including obese individuals (Horie et al. 2008). Relatively to $A C$, this anthropometric data has been shown to be the most suitable anthropometric data to evaluate body fat distribution, as well as to quantify the risk of obesityrelated health disorders, such as cardiovascular diseases (Paniagua et al. 2008; Carmo et al. 2008; WHO 2016).

\subsection{The Infrared Thermography (IRT) as a diagnosis and assessment tool}

Concerning workplaces with lifting tasks, one of the crucial elements in WRMSD prevention deals with the understanding of muscular demands associated with too frequently performed tasks (Butler et al. 2009; Antwi-Afari et al. 2017, 2018). In this context, IRT has been identified as an alternative technique for physiological response measurement due to exposure to WRMSD risk factors (Bertmaring et al. 2008). In fact, the use of IRT has the advantage to be a completely non-invasive and non-ionising technique (Jones and Plassmann 2002; Ludwig et al. 2014) and can be applied even during pregnancy (Pereira et al. 2016).

In medicine, the IRT applicability is based on the fact that the 130 human skin emits continuously infrared radiation, being its body distribution symmetrical in a healthy person. Therefore, avoiding the use of biologically ionising radiation, IRT is an effective alternative to conventional imaging techniques (Casanova et al. 2018) for a large number of diseases related to peripheral circulation, such as, for example, diabetic foot disease (Carbonell et al. 2018; Seixas et al. 2018), ankle injuries (Oliveira et al. 2016) and knee diseases (Calin et al. 2015). Recent technological advances in IRT imaging have extended its use to different clinical purposes as a diagnosis complementary technique for musculoskeletal and vascular disorders, oncology and sports medicine (Ring 2006; Santos et al. 2014), with basis on the identification of normal and abnormal surface Skin Temperature $\left(T_{\text {skin }}\right)$ patterns (Bertmaring et al. 2008).

The $T_{\text {skin }}$ depends on the combination of energy expenditure, nutrient metabolism, and blood flow, being its variations reflected on physiological responses of the tissues during physical activity (Santos et al. 2014). Different exploratory studies (Table 1) have shown that $T_{\text {skin }}$ variations are associated with exposure to specific WRMSD risk factors, considering work tasks with repetitive muscular work, including typing in a work office (Vardasca et al. 2008; Gold et al. 2010), and in tasks with static (Bertmaring et al. 2008) and intermittent exertions, such as overhead tapping tasks involving muscles of shoulders and arms (Barker et al. 2006; Govindu and Babski-Reeves 2012).

In the mentioned studies in Table 1, the authors intended to test different work conditions (simulated in laboratory settings) on $\mathrm{T}_{\text {skin }}$ in certain body regions. For example, Barker et al. (2006), simulating tasks frequent at the automotive assembly industry, test the effect of activity duration and hands height-location. In this context, Bertmaring et al. (2008) studied tasks with static hand contractions head-above, performed until the participants' exhaustion, considering different loads and shoulders' angles. The results showed that the thermographic data are more sensitive to the shoulders' angular variability than to the loads' variability. In turn, the typing task was a work activity studied by Vardasca et al. (2008) and Gold et al. (2010) through thermograms of hands' dorsal view. Globally, these studies demonstrated that different occupational conditions produce significant changes in the recorded thermograms; concluding that the thermography is sensitive to the variation of the conditions under which the tasks are performed, and can constitute a valid technique for assessing the WMSD risk factors. In this field, Govindu and BabskiReeves (2012) demonstrated the reliability of the values data obtained for the anterior deltoid during muscle activity with the hands above head, simulating frequent screwing automotive assembly industry, in comparison with psychophysical perceptions of exertion.

These exploratory studies have shown that variations in $T_{\text {skin }}$ are related to physiological responses to certain occupational conditions. One of the advantages associated with IRT application in the WMSD risk assessment is that this technique helps to explain physiological mechanisms related to these disorders' genesis.

\subsection{Research opportunity and objectives}

In recent years, obesity has been intensively studied, nevertheless the effect of excess fat mass on the function of the locomotor system is still unclear and more biomechanical and physiological studies are required to provide a complete 
Table 1. Summary of previous studies that applied IRT to study work tasks.

\begin{tabular}{|c|c|c|c|c|}
\hline Reference & Objective(s) & Sample & ROI studied & Principal Conclusion(s) \\
\hline Barker et al. 2006 & $\begin{array}{l}\text { To study the effects of working } \\
\text { pace and hands' height during } \\
\text { screwing tasks. }\end{array}$ & 6 men and 6 women & $\begin{array}{l}\text { Medium deltoid } \\
\text { and trapezius. }\end{array}$ & $\begin{array}{l}\text { IRT is sensible to identify the } \\
\text { occupational conditions } \\
\text { variability. }\end{array}$ \\
\hline Bertmaring et al. 2008 & $\begin{array}{l}\text { To analyse skin temperature } \\
\text { differences during static muscle } \\
\text { work with the hand above the } \\
\text { head, along with different } \\
\text { shoulder angles and loads. }\end{array}$ & 5 men and 5 women & Anterior deltoid & $\begin{array}{l}\text { The thermographic data are } \\
\text { more sensitive to } \\
\text { shoulders' angular } \\
\text { variability than loads' } \\
\text { differences. }\end{array}$ \\
\hline Vardasca et al. 2008 & $\begin{array}{l}\text { To identify factors that influence } \\
\text { the thermographic changes } \\
\text { during typing tasks. }\end{array}$ & 12 healthy volunteers & $\begin{array}{l}\text { Hands' posterior } \\
\text { view. }\end{array}$ & $\begin{array}{l}\text { The } \mathrm{T}_{\text {skin }} \text { variation is } \\
\text { influenced by individuals' } \\
\text { dexterity, age, and BMI. }\end{array}$ \\
\hline Gold et al. 2010 & $\begin{array}{l}\text { To relate } T_{\text {skin }} \text { differences to blood } \\
\text { flow during typing tasks. }\end{array}$ & 11 office workers & $\begin{array}{l}\text { Hands' posterior } \\
\text { view. }\end{array}$ & $\begin{array}{l}\text { The hands' } \mathrm{T}_{\text {skin }} \text { depends on } \\
\text { blood flow. Typing speed } \\
\text { influences temperature, } \\
\text { which may be an indicator } \\
\text { of musculoskeletal } \\
\text { problems at the } \\
\text { extremities. }\end{array}$ \\
\hline Govindu and Babski-Reeves (2012) & $\begin{array}{l}\text { To test the reliability of the } \\
\text { thermographic data obtained } \\
\text { during screwing tasks above the } \\
\text { head. Correlate thermal changes } \\
\text { with psychophysical } \\
\text { perceptions of exertion. }\end{array}$ & 24 participants & Anterior deltoid. & $\begin{array}{l}\text { IRT demonstrates reliability as } \\
\text { a risk assessment } \\
\text { technique. Lower } \\
\text { temperatures are related } \\
\text { to increased } \\
\text { psychophysical discomfort. }\end{array}$ \\
\hline
\end{tabular}

picture of obesity effects on work performance, including during manual lifting loads (Park et al. 2009; Singh et al. 2009; Williams and Forde 2009; Sangachin and Cavuoto 2016; Corbeil et al. 2019). Additionally, in the authors' best knowledge the present work is a pioneer study for IRT application with a heterogeneous sample (obese and non-obese participants) during lifting tasks.

Therefore, concerning different Regions Of Interest (ROI), an objective of the current study was to test whether $T_{\text {skin }}$ changes were sensitive to work conditions of lifting tasks, with the purpose to support the potential of IRT application in WRMSD risk factors assessment during biomechanics studies. Another objective of this investigation was to analyse possible differences in $T_{\text {skin }}$ changes across individuals with different obesity levels, during the predefined task.

\section{Materials and method}

\subsection{Participants}

A total of 29 healthy participants, including non-obese and obese, engaged in this research work. All participants reported that they did not have at present any type of musculoskeletal disorders and signed an informed consent. The participants received a briefing on the study objectives, nature, and potential risks. Different anthropometric data were collected, namely: BMI, $\mathrm{AC}$ and BFM percentage determined by BIA. However, and as mentioned above, for the sample characterisation only participants' AC and BFM were applied. This last-mentioned parameter was quantified utilising an OMRON BF $306^{\circ}$ Body Fat Monitor (OMRON, Netherlands). This equipment not only allows for measurement of the BFM percentage by considering the BIA and also permits the integration of personal data, such as participants' height, weight, age, and gender, in order to accurately define the individual obesity level (Deurenberg et al. 1998). The interpretation of $A C$ values the occurrence of two risk levels were considered, such as (i) increased risk ( $A C \geq 80 \mathrm{~cm}$ for women and $94 \mathrm{~cm}$ for men); (ii) very increased risk ( $A C \geq 88 \mathrm{~cm}$ for women and $102 \mathrm{~cm}$ for men) (Carmo et al. 2008).

Individuals with asymmetric infrared imaging of the body regions considered (greater than $0.5^{\circ} \mathrm{C}$ ) were excluded, based on the statement of asymmetrical images, which have been related to neurological disorders (as applied by Govindu and Babski-Reeves 2012).

Furthermore, the participants were instructed to avoid smoking, alcohol or liquids and eating any food at least two hours before performing the test. In addition, a preliminary visual inspection of the body areas considered was performed for each participant, with the aim of ensuring that they do not have scars or other skin abnormalities, which can influence the thermal data.

\subsection{Experimental design and procedure}

The adopted research design was a deductive approach, characterised by the search of explanations and testing about causal relations between variables (Saunders et al. 2007). This was an experimental study developed into a research laboratory. Before the experimental trial performance, the participants acclimatised, themselves for 15 minutes for promoting the thermal equilibrium with the surrounding laboratory stabilised, environment conditions, namely: mean relative humidity at $58.2( \pm 1.7) \%$ and mean temperature at $23.3( \pm 1.2){ }^{\circ} \mathrm{C}$. According to the internationally accepted guidelines (Ammer and Ring 2000), during the acclimatisation period, the participants stayed with no direct ventilation, fluorescent lighting, clothing, accessories, and hair over the body regions of arms, neck and upper trunk.

The provocative test consisted of repeated lifting tasks, with a load of $7 \mathrm{~kg}$. Considering previous studies focused on IRT application to study working tasks (Barker et al. 2006; Bertmaring et al. 2008; Vardasca et al. 2008; Gold et al. 2010; 
Govindu and Babski-Reeves 2012), it was defined that the lifting task would have to be repeated over a certain period to cause a musculoskeletal overload sufficient to produce physiological changes noticeable by the IRT. Therefore, pilot tests were performed with two volunteers, considering different loads, task frequencies and durations. Through these tests, it was defined that the load would be $7 \mathrm{~kg}$, as in Dolan et al. (1999) and Meyers and Keir (2003), and it would be manipulated for a maximum of 2 minutes to prevent muscle fatigue associated with lactic acid production on the muscles (which influences thermographic results). Then, based on the application of the NIOSH '91 Equation (Waters et al. 1993), a safe periodicity for the handlings of approximately seven seconds was considered.

During the experimental trials, the participants lifted the load between the floor and shoulders height and replaced it to the floor. As in several previous studies focused on the assessment of physical overload during lifting tasks (Dolan et al. 1999; McKean and Potvin 2001; Singh et al. 2009; among others), the vertical amplitude of handling has taken into account the participants' anthropometric data. With this experimental design, the scenario of frequent vertical amplitudes was intended, such as lifting loads between the floor and workbenches. During this test, a frequent work condition that compromises the workers' posture was simulated, such as the presence of a physical barrier between worker and load. In this constrained scenario, the load was placed behind a $60 \mathrm{~cm}$ (120\% of average male and female knee heights) high barrier, simulating one side of an industrial bin (as tested by McKean and Potvin 2001). The experimental apparatus is schematised, in Figure 1.
With the aim of mimicking a realistic working performance, the participants were allowed to adopt their preferred handling technique relatively to posture adopted (as defended by Kingma and van Dieën 2004; Plamondon et al. 2017; Corbeil et al. 2019). However, the feet position was also defined by each participant in order to maintain the load close to the body and maintain a similar position across the lifting and lowering trials (as applied by Sangachin and Cavuoto 2016). With this purpose, before the experiment data acquisition, participants were allowed to simulate the task of box lifting and lowering.

\subsection{Thermographic imaging and data processing}

Before and after the task performance, thermal images, including the considered $\mathrm{ROI}$, from anterior and posterior corporal views were registered by using an uncooled FLIR $^{\circledast}$ E60sc thermal camera (FLIR Systems, Wilsonville, Oregon, USA). The infrared camera (Figure 2) includes a focal plane array (FPA) sensor size of $320 \times 240$, Noise Equivalent Temperature Difference (NETD) of $<50 \mathrm{mK}$ at $30^{\circ} \mathrm{C}$ and measurement uncertainty of $\pm 2 \%$ of the overall temperature range reading. During the images acquisition, participants were stood up in front of a uniform background. The value of human skin emissivity used is in line with the majority of previous studies (Bernard et al. 2013; Fernández-Cuevas et al. 2015), being set to 0.98. The distance between the IRT camera and the subject was kept constant and equal to one metre.

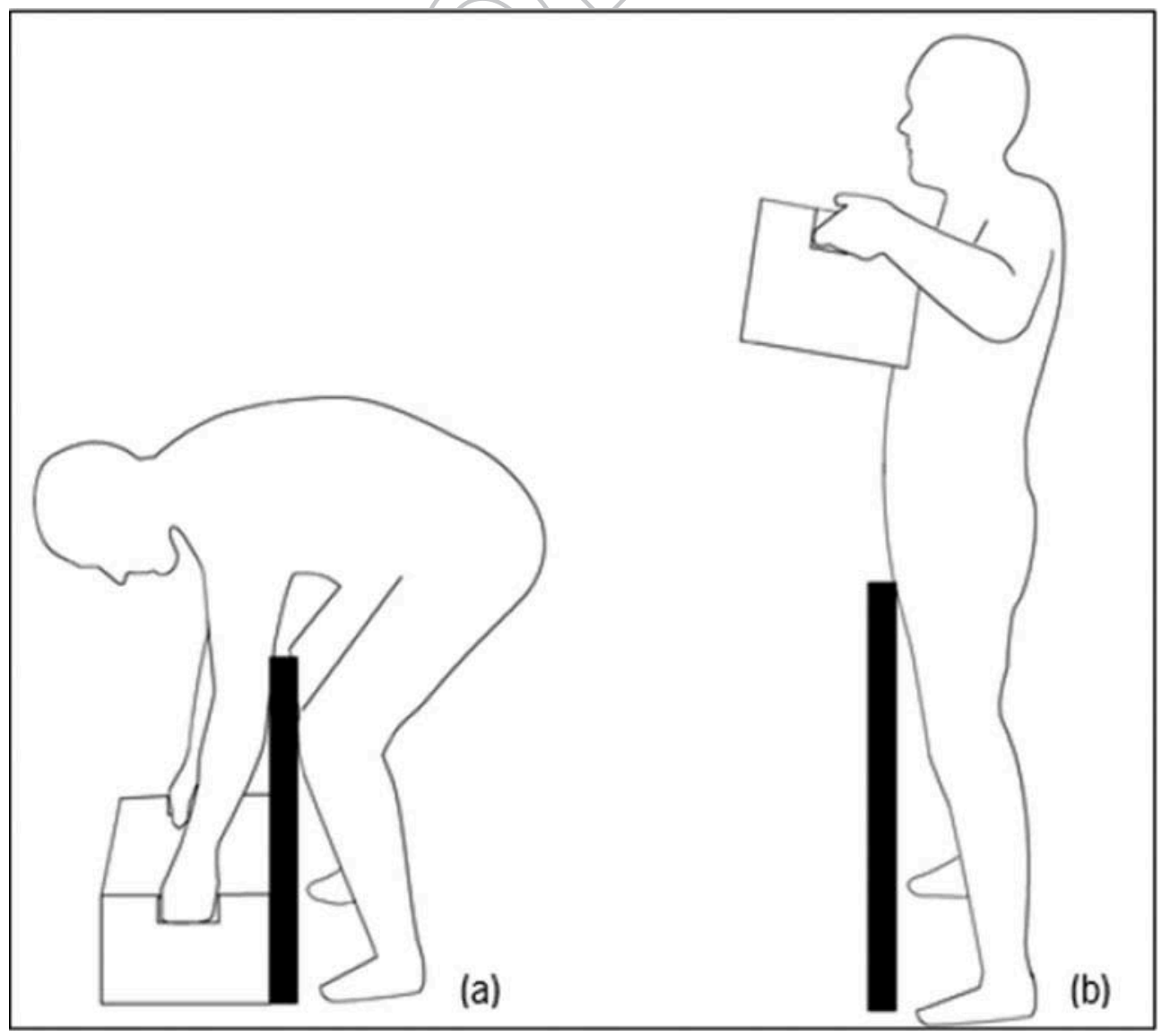

Figure 1. Representation of the (a) initial and (b) final position of the lifting. 


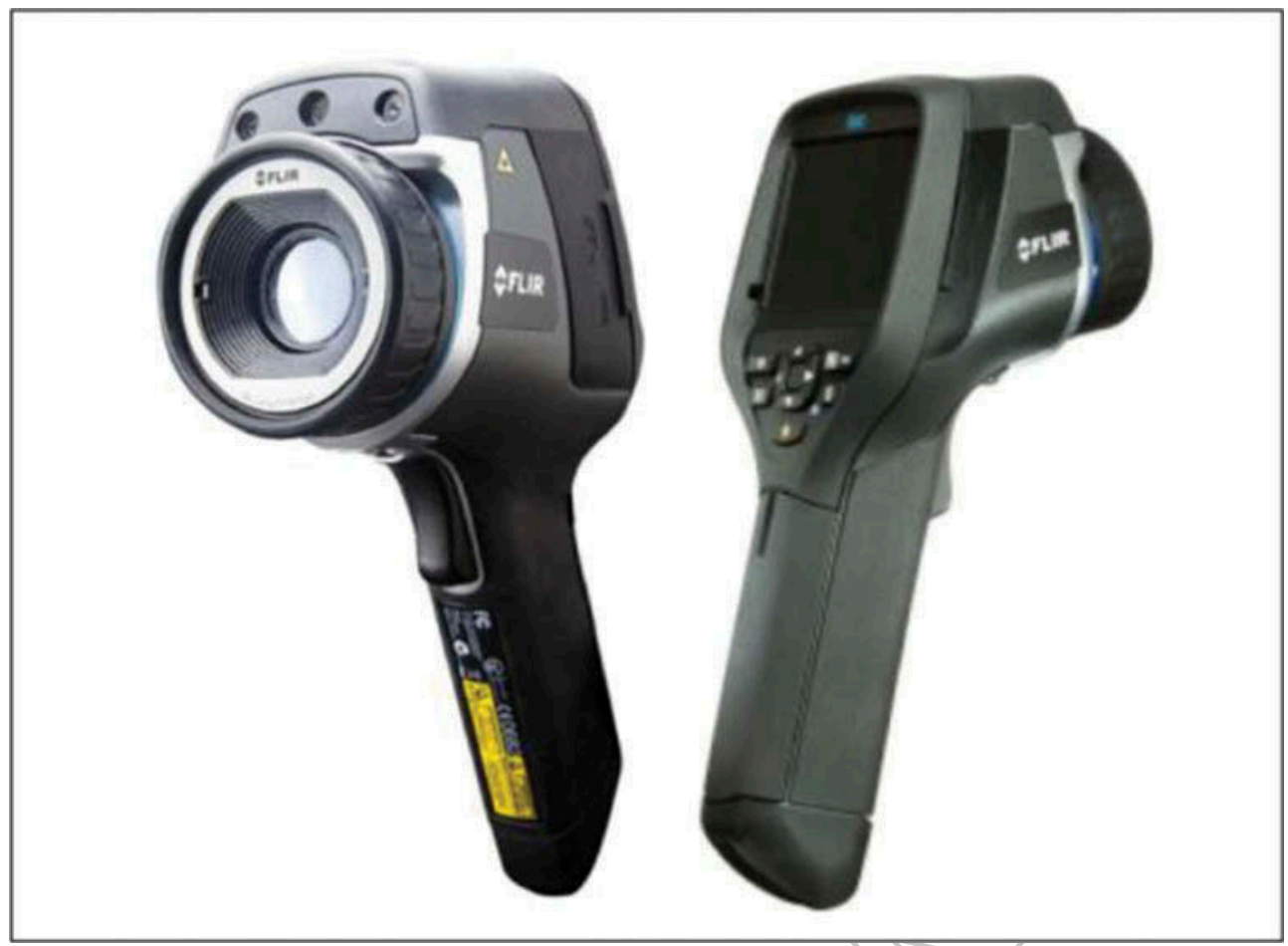

Figure 2. Infrared camera used in the current study (image courtesy by FLIR ${ }^{\circledR}$ Company).

The IRT imaging analysis was performed with the FLIR ThermaCAM Researcher pro 2.10 software (FLIR Systems, Wilsonville, Oregon, USA) and according to the selection of 16 different ROI. Eight of these regions were from anterior body view, as defined in Figure 3, namely: left and right shoulders joint (ROI 01 and 02, respectively), upper ligaments of left and right shoulders (ROI 03 and 04), lower ligaments of left and right shoulders (ROI 05 and 06), left and right arms (ROI 07 and 08). The remaining eight $\mathrm{ROI}$ were from posterior body view, as represented in Figure 4, namely: left and right shoulders joint (ROI 01 and 02), left and right sides of half of neck (ROI 03 and
04), left and right trapezius (ROI 05 and 06), left and right arms (ROI 07 and 08).

The Glamorgan protocol was considered in the ROI definition (Ammer 2008). The ROI selection was based on the muscles functionality and articulations involved in this type of handling tasks and in an attempt to avoid body regions with high fat mass accumulation (such as the abdominal region), which might have an undesired effect on the thermographic data (Savastano et al. 2009; Fernández-Cuevas et al. 2015). The analysis software allows for the quantification of the mean of $\mathrm{T}_{\text {skin }}$ across the different ROI mentioned before.

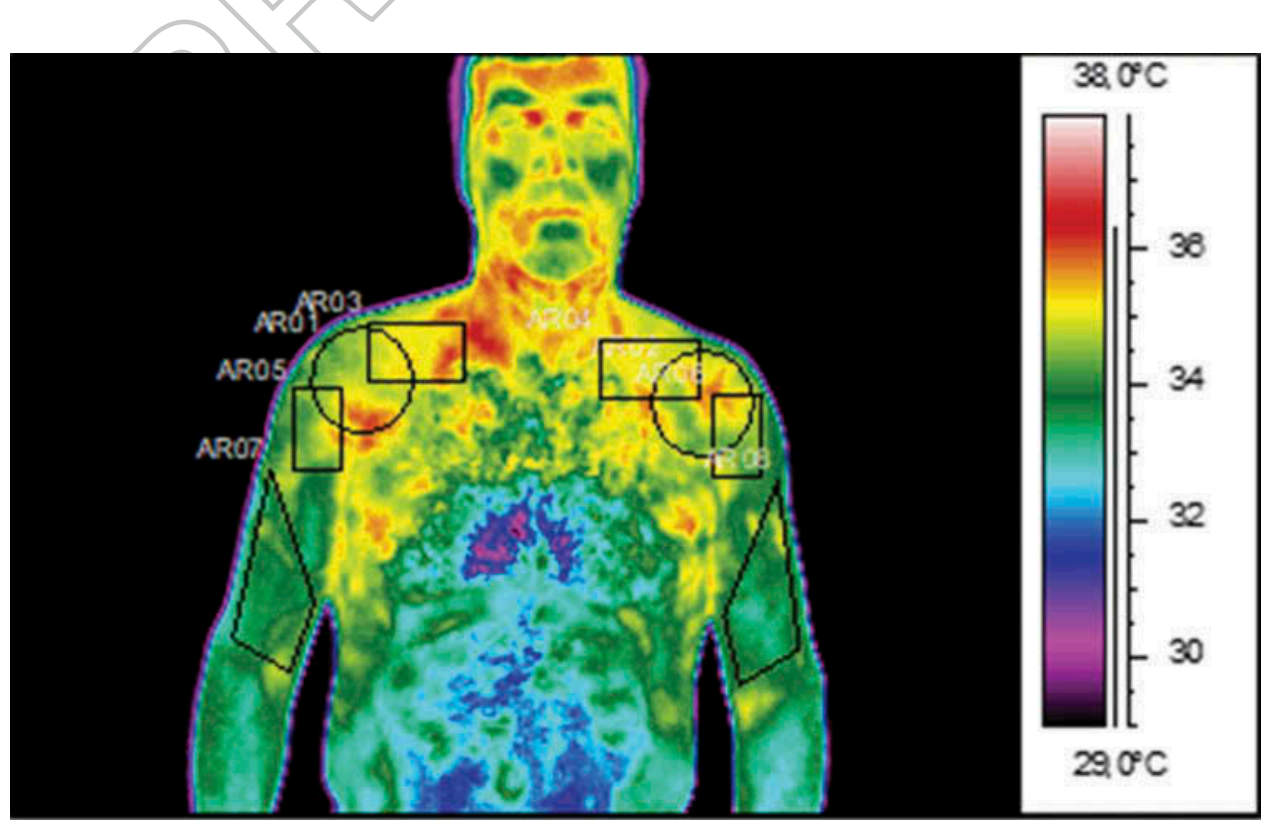

Figure 3. Example of a thermal image for anterior view with the Regions Of Interest (ROI) defined. 


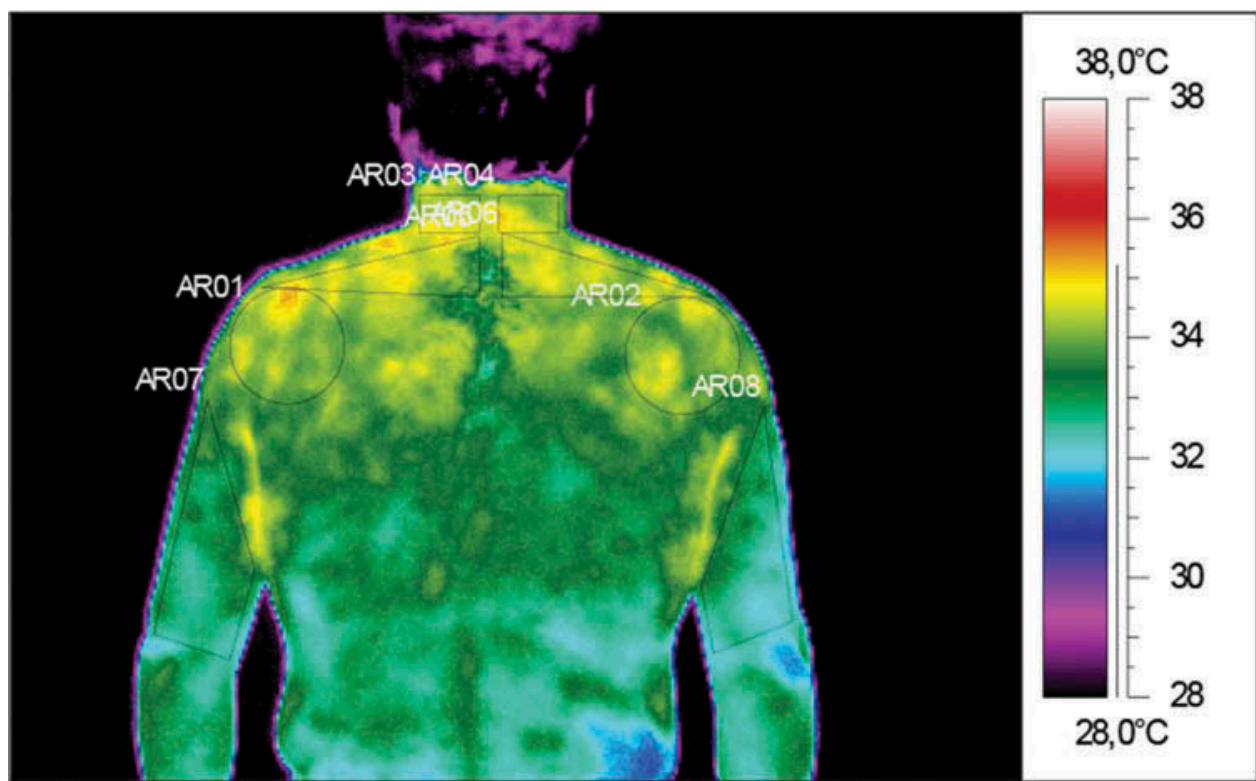

Figure 4. Example of a thermal image for posterior view with the Regions Of Interest (ROI) defined.

Considering the sample with participants with different levels of obesity, also subcutaneous fat can influence the $T_{\text {skin }}$ distribution (Fernández-Cuevas et al. 2015), the data analysis was done from the temperatures differential $(\Delta T)$ calculated at each ROI. Based on previous studies (Quesada et al. 2015; Formenti et al. 2016; Rossignoli et al. 2016), $\Delta$ T was calculated by the algebraic difference between $\mathrm{T}_{\text {skin }}$ measured after the handling load performance minus basal temperature measured before the task. This calculation was performed with the purpose to normalise the data across the subjects with different levels of obesity. The $\Delta T$ values could be either positive or negative, depending on whether $T_{\text {skin }}$ increased on decreased during the handling task.

\subsection{Statistical analysis}

The statistical analysis was conducted utilising the $\mathrm{IBM}^{\oplus} \mathrm{SPSS}^{\oplus}$ Statistics 24.0 software. Shapiro-Wilk normality tests were performed on all continuous data.

For the sample characterisation ${ }^{2}$ the descriptive statistics were applied, being the mean used as a measure of central tendency, and the standard deviation (SD) as a measure of dispersion. After verifying the normality of the data, Pearson correlation tests were applied to evaluate if anthropometric data (BFM, AC, and BMI) are associated with the thermal data.

Considering the normality of the means $\mathrm{T}_{\text {skin }}$ registered before and after the task for each ROI, Student's $t$-tests were applied to verify the systematic difference between each couple of data set. Descriptive analysis was also used to present $\Delta T$ data (mean values and SD) across the different groups of participants (defined by their levels of obesity). Finally, to determine the strength of the relationship of the $\Delta T$ values and obesity, Pearson correlations were computed. Thus, it was intended to test if the increase of obesity level (measured by the different anthropometric data, as $\mathrm{BFM}, \mathrm{AC}$, and $\mathrm{BMI}$ ) is related to the increasing/decreasing of the $\Delta \mathrm{T}$. Significance was determined for a probability value $p<0.05$.

\section{Results and discussion}

\subsection{Sample characterisation}

Considering the results obtained by BIA and $\mathrm{AC}$ assessment, the sample was divided across three levels of obesity, namely: (i) normal $(n=11)$; (ii) high $(n=10)$; and (iii) very high $(n=8)$ (Table 2).

Since the normality of the data was verified, the Pearson correlation was applied and statistically significant linear correlations between the anthropometric variables were evidenced, as it is shown in Table 3. The results indicate that the BFM increasing is positively BMI increasing, as well as to the $A C$ increasing, the same relation is statistically significant between the $\mathrm{BMI}$ and $\mathrm{AC}$ of the participants.

These correlations are corroborated with the available literature (Singh et al. 2009; Beechy et al. 2012). However, it should be highlighted that the comparative study or correlation between these anthropometric is not one of the main objectives of the present study. These different data were considered with the purpose of characterising and categorising the sample in a more complete manner, as proposed by Singh et al. (2009).

\subsection{Differences in $T_{\text {skin }}$ between before and after the lifting task}

Through Student's $t$-tests, it was observed that the difference between the means $T_{\text {skin }}$ recorded after and before the handling task has evidence of being statistically significant for all ROI considered, as it is demonstrated in Tables 4 and 5 .

These significant differences between mean temperatures allow proving the viability of the IRT as an effective alternative technique to identify physiological changes, through thermal imaging differences, caused by exposure to WRMSD risk factors, in this case factors related to the lifting tasks. Previous studies have already demonstrated similar evidence, but for other kind of activities, such as tapping tasks with arms maintained above 
Table 2. Mean (SD) of personal data used in the sample characterisation across the different levels of obesity.

\begin{tabular}{lccc}
\hline & & \multicolumn{2}{c}{ Obese } \\
\cline { 3 - 4 } & Non-obese & High & \\
$(n=11)$ & $(n=10)$ & $\begin{array}{c}\text { Very High } \\
(n=8)\end{array}$ \\
\hline BFM $(\%)$ & $24.7(8.0)$ & $28.1(3.8)$ & $33.3(7.1)$ \\
AC $(\mathrm{cm})$ & $79.9(6.7)$ & $87.5(6.6)$ & $108.4(6.9)$ \\
BMI $\left(\mathrm{kg} / \mathrm{m}^{2}\right)$ & $22.4(1.5)$ & $25.6(2.4)$ & $31.2(3.3)$ \\
Age (years old $)$ & $33.9(10.8)$ & $37.0(10.9)$ & $34.9(8.8)$ \\
\hline
\end{tabular}

Table 3. Summary of Pearson correlation between the values of anthropometric data $(n=29)$.

\begin{tabular}{lc}
\hline & $r$ coefficient \\
\hline BFM and BMI & $0,693^{* *}$ \\
BFM and AC & $0,462^{*}$ \\
BMI and AC & $0,898^{* *}$ \\
\hline
\end{tabular}

Legend: * statistical significance at $p<0.05$ and ${ }^{* *} p<0.01$.

Table 4. Mean (SD) of $\mathrm{T}_{\text {skin }}$ before and after the task for anterior view, and respectively statistical significance for the difference between these temperatures $(n=29)$.

\begin{tabular}{lccc} 
& \multicolumn{2}{c}{$\mathrm{T}_{\text {skin }}\left({ }^{\circ} \mathrm{C}\right)$} \\
\cline { 2 - 3 } $\begin{array}{l}\text { ROI } \\
\text { (Anterior) }\end{array}$ & Before task & After task & $p$-value \\
\hline 01 & $33.52(0.72)$ & $33.16(0.87)$ & $0.020^{*}$ \\
02 & $33.40(0.80)$ & $33.10(0.86)$ & $0.014^{*}$ \\
03 & $33.73(0.70)$ & $33.42(0.83)$ & $<0.01$ \\
04 & $33.70(0.76)$ & $33.38(0.83)$ & $<0.01$ \\
05 & $33.33(0.78)$ & $32.98(0.92)$ & $<0.01$ \\
06 & $33.26(0.85)$ & $32.93(0.90)$ & $<0.01$ \\
07 & $32.60(0.93)$ & $32.25(0.94)$ & $<0.01$ \\
08 & $32.45(0.96)$ & $32.16(0.90)$ & $0.020^{*}$ \\
\hline
\end{tabular}

Legend: *statistical significance at $p<0.05$.

Table 5. Mean (SD) of $\mathrm{T}_{\text {skin }}$ before and after the task for posterior view, and respectively statistical significance for the difference between these temperatures $(n=29)$.

\begin{tabular}{llll}
\hline & \multicolumn{2}{c}{$\mathrm{T}_{\text {skin }}\left({ }^{\circ} \mathrm{C}\right)$} & \\
\cline { 2 - 3 } $\begin{array}{l}\text { ROI } \\
\text { (Posterior) }\end{array}$ & Before task & After task & $p$-value \\
\hline 01 & $33.30(0.80)$ & $32.73(0.86)$ & $<0.01$ \\
02 & $33.24(0.81)$ & $32.62(0.91)$ & $<0.01$ \\
03 & $34.21(0.77)$ & $33.70(0.87)$ & $<0.01$ \\
04 & $34.14(0.73)$ & $33.66(0.90)$ & $<0.01$ \\
05 & $33.85(0.74)$ & $33.35(0.88)$ & $<0.01$ \\
06 & $33.86(0.72)$ & $33.31(0.89)$ & $<0.01$ \\
07 & $31.47(0.91)$ & $31.08(0.87)$ & $<0.01$ \\
08 & $31.54(0.94)$ & $31.12(0.89)$ & $<0.01$ \\
\hline
\end{tabular}

the head (Barker et al. 2006; Govindu and Babski-Reeves 2012), and typing tasks in a work office (Vardasca et al. 2008; Gold et al. 2010). However, it can be stated that the current work is an innovative and precursor study in application of IRT as an assessment technique of WRMSD risk related to lifting tasks, which has not been addressed in the literature.

The mean values presented in Tables 4 and 5 demonstrated the occurrence of a negative difference between $T_{\text {skin }}$ measured before and after the task, verifying a statistically significant cooling of all ROI after the task. This evidence is in agreement with the literature (Torii et al. 1992; Johnson 1992; Formenti et al. 2016), which supports that the temperature of the skin begins to decrease with the beginning of dynamic exercise, due to the vasoconstriction caused by muscular work.

\section{3. $\Delta T$ across subjects with different obesity levels}

In order to better understand the mentioned difference between the temperatures registered before and after the task, and for the comparison of the cooling amplitude across the heterogeneous sample, the $\Delta \mathrm{T}$ was calculated and analysed, for each ROI. Descriptive statistics for $\Delta \mathrm{T}$, considering the sample division across the three levels of obesity defined, are provided in the plots of Figure 5.

Analysing $\Delta T$ negative values between-levels, it is verified that the cooling tends to be higher for individuals with higher levels of obesity. Additionally, it was assessed if the cooling of surface skin after the task is correlated to the increasing level of obesity, according to anthropometric data values. Summaries of the statistical significance of the correlations between each anthropometric variable considered (AC, BFM, and BMI) and $\triangle T$ from anterior and posterior/views, obtained through the Pearson correlation test, are presented in Tables 6 and 7.

Supporting the evidence found by analysing the plots of Figure 5, the Pearson test shows that a negative correlation occurs between the variables considered, in the sense that the linear increase of participants' anthropometric data (BFM, AC, and $\mathrm{BMI}$ ) is related to decrease of $\Delta T$ values. However, this correlation presents evidence of statistical significance only in five of the ROI studied, corresponding to regions at shoulders and arms, and considering the AC values.

This observation corroborates the study developed by Shiri et al. (2013), in which a positive correlation was found for AC increase and back pain. Pryce and Kriellaars (2014) also reported that the increase of BFM in the trunk region causes a modification of the body centre of mass, which eventually leads to the increase of compressive forces and moment acting on L5-S1 during handling loads tasks. These indicators point out that the $A C$ seems to be a relevant indicator, regarding the probability of an increase in musculoskeletal overload during these tasks.

Regarding the decrease of $\mathrm{T}_{\text {skin }}$ after the task (evident in $\Delta \mathrm{T}$ negative values), as aforesaid, this is in agreement with several previous studies, which evidenced a cooling in different body parts after performing activities, with dynamic and static muscular exertions (Torii et al. 1992; Barker et al. 2006; Merla et al. 2010; Formenti et al. 2016). It is also known that the increase of this cooling is related to changes in blood flow (Gold et al. 2010), namely to vasoconstriction. Tanimoto et al. (2009) demonstrated that during continuous performance of lifting and lowering a load, even with a slow movement, suppression of blood inflow and outflow occurs in involved muscles, increasing their deoxygenation. From the foregoing, it is considered that the $\mathrm{T}_{\text {skin }}$ cooling, registered in the present study, is also due to vasoconstriction, potentiating the increase of incidence probability of musculoskeletal problems. Thus, for example, one of the causes of WRMSD at the shoulders is the insufficient blood flow in the tendons due to muscle contraction and the pressure exerted by the surrounding bones during tasks involving the arms flexion (Hagberg and Wegman 1987). 

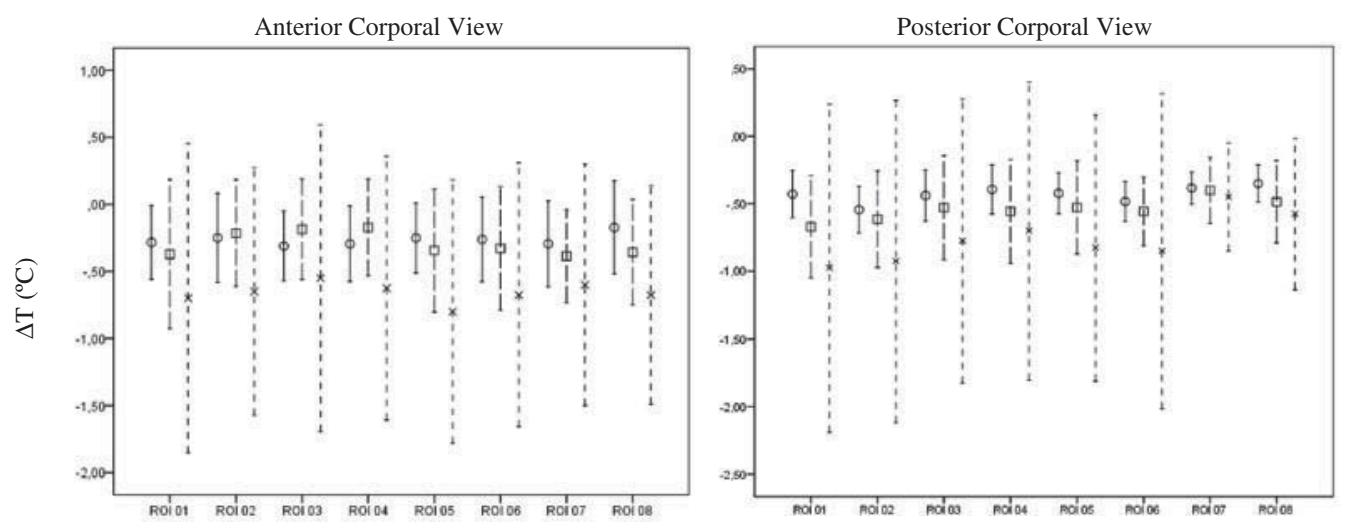

Figure 5. Representation of the $\Delta \mathrm{T}$ mean values for anterior and posterior ROI across the different participants' levels of obesity. Error bars denote SD. Legend: $0-$ normal; $\square-$ high; $x$ - very high.

Table 6. Summary of Pearson correlation between values of anthropometric data and $\Delta \mathrm{T}$ of anterior corporal view $(n=29)$.

\begin{tabular}{lcccccccc}
\hline & \multicolumn{7}{c}{$r$ coefficient across ROI of anterior view } \\
\cline { 2 - 9 } & 01 & 02 & 03 & 04 & 05 & 06 & 07 & 08 \\
\hline BFM & -0.146 & -0.111 & -0.099 & -0.108 & -0.116 & 0.007 & -0.085 & -0.095 \\
AC & $-0.390^{*}$ & -0.312 & -0.182 & -0.237 & $-0.415^{*}$ & $-0.358^{*}$ & -0.264 & $-0.354^{*}$ \\
BMI & -0.312 & -0.240 & -0.150 & -0.183 & -0.339 & -0.227 & -0.223 & -0.298 \\
\hline
\end{tabular}

Legend: *statistical significance at $p<0.05$.

Table 7. Summary of Pearson correlation between values of anthropometric data and $\Delta \mathrm{T}$ of posterior corporal view $(n=29)$.

\begin{tabular}{lcccccccc}
\hline & \multicolumn{7}{c}{$r$ coeficient across ROI of posterior view } \\
\cline { 2 - 9 } & \multicolumn{1}{c}{01} & 02 & 03 & 04 & 05 & 06 & 07 & 08 \\
\hline BFM & -0.080 & -0.066 & -0.076 & -0.109 & -0.149 & $-0,145$ & 0.091 & -0.176 \\
AC & $-0.354^{*}$ & -0.182 & -0.204 & -0.265 & -0.328 & $-0,238$ & -0.050 & -0.249 \\
BMI & -0.317 & -0.184 & -0.176 & $-0,232$ & -0.298 & -0.237 & 0.027 & -0.256 \\
\hline
\end{tabular}

Legend: *statistical significance at $p<0.05$.

It should also be noted that individuals' AC can interfere with the performance of lifting tasks, especially when its present postural restrictions, such as the existence of a physical barrier considered in the present investigation. The increase of the fat mass in the abdominal region with the existence of the physical barrier contributes to the increase of the horizontal distance between the load and the worker's body. This horizontal distance constitutes an important risk factor for WRMSD during these tasks (Waters et al. 1993), particularly higher values of the distance directly related to higher values of moments acting on the spine, and consequently with higher muscle contractions (Potvin et al. 1991). As it was mentioned previously, the increase of muscle contractions may increase vasoconstriction (Torii et al. 1992; Johnson 1992) and, consequently, decrease the $T_{\text {skin }}$ of the affected regions. The obtained results are in agreement with this evidence, pointed out to the fact that obesity contributed to the cooling increase, meaning that, most probably, occurred higher vasoconstriction in obese, as consequence an increased muscular overload related to the lifting task performance. However, the correlation between $T_{s k i n}$ cooling and obesity described in this study deserves further analysis on a larger sample and, probably, considering a blood flow monitoring tool and the collection of other physiological and biomechanical data (e.g. kinematics and electromyographic). In addition, it may be important to include other handling tasks with different occupational risk factors.
Finally, it should be noticed that to the authors' best knowledge, this is the first study that addresses the IRT imaging application to study manual lifting tasks and with a heterogeneous sample, including non-obese and obese subjects. Therefore, the $\mathrm{ROI}$ selection was conditioned by this factor, avoiding areas with frequently higher fat mass accumulation. The fact that the sample considered is heterogeneous, it can conditioned the thermographic results and, consequently, the higher $\Delta T$ values variability within groups (Figure 5) and few correlations with statistical significance (Tables 6 and 7). In Ludwig et al. (2014) a heterogeneous sample was also used (including sedentary individuals and swimming athletes between 15 and 45 years) in which they compared different ways of analysing the thermographic data, including the determination of the mean temperature by $\mathrm{ROI}$ (as performed in the present study). These authors verified that this analysis method is effective, even for a heterogeneous sample, allowing an ROI adequacy to different anatomical characteristics. However, they emphasised, that $T_{\text {skin }}$ depends on anatomical factors, such as the presence of different types of subcutaneous tissues (adipose mass and muscle mass).

In the present work, with the purpose to avoid the influence of fat mass on thermographic results, different methodological options were adopted. In addition to the careful ROI selection, $\Delta T$ was calculated (as applied by Formenti et al. 2016; Quesada et al. 2015; Rossignoli et al. 2016), and the comparison of the 
thermographic data between subjects was done using $\Delta T$ values. It is considered that the $\Delta \mathrm{T}$ determination helped to circumvent this limitation, since mean $\mathrm{T}_{\text {skin }}$ (as applied by Ludwig et al. 2014) are not being compared, but rather the differences between mean temperatures before and after the task. It should be noted that there is an evidence that during physical exercise the distribution of temperatures throughout the skin of the whole body is not related to the distribution of body fat (Fournet et al. 2013). Nevertheless, the relation between the fat mass influence on the skin temperature distribution needs further investigation (Fernández-Cuevas et al. 2015).

In short, the current research can be useful to better understand and emphasise the importance of studying the obesity effects on IRT imaging during lifting tasks and also has illustrated the importance of future research in the field of investigation.

\subsection{Limitations and future work}

The current study has several limitations that need to be stressed. Firstly, the most lifting tasks that occur in real workplaces are not scaled. It is also likely that differences may exist between tasks with different constraints and loads. Increasing

540 the sample size might be another option for future investigation. Despite this, in the current study, the obtained data demonstrated statistical validity.

The research work was limited to the ROI studied, since this selection was influenced by the functionality of the muscles existing at these body regions, trying to avoid corporal areas with higher fat mass accumulation. However, as mentioned earlier, the data analysis was developed considering the $\Delta T$, which increased the accuracy of data analysis.

As future work, the development of physiological and biomechanical studies could be an important research direction, which allows for a better understanding of the physiological mechanisms that could increase musculoskeletal overload and, consequently, increase thermal changes at the $\mathrm{T}_{\text {skin }}$.

The IRT application is a recent research approach in the field of WRMSD assessment and few working tasks have already studied. Based on this evidence, it must be highlighted that this research topic could be widely explored. In this field, as advantageous characteristics of this technique are the fact that does not need to fix sensors at the workers body which can compromise the normal movements during dynamic tasks, as well as the data collecting and processing is easily developed (comparing with other techniques applied in this context, such as surface electromyography). However, the IRT has the limitation of having to be applied in a controlled environment (concerning the temperature and relative humidity).

In summary, the current findings are in line with the existing literature, and the current study can be seen as a good starting point for future investigation in the field.

\section{Conclusions}

Obesity is growing among the industrialised,workforce and this individual condition can be assessed using different techniques (e.g. AC, BFM assessed by BIA and BMI). However, in specific studies focused on obesity effects during occupational tasks, this assessment should include relevant anthropometric data that may interfere with the performance of the tasks, such as AC during the dynamic lifting tasks.

The present research work proved that IRT imaging presents enough evidence to detect thermal differences (in this case, a significant cooling at all ROI studied) after exposure to risk factors associated with lifting tasks.

Additionally, the results demonstrated that obese workers tend to present a higher $\mathrm{T}_{\text {skin }}$ cooling after the performance of these tasks when compared with non-obese. This evidence supports the idea that obesity constitutes a WRMSD risk factor during lifting tasks since the $T_{\text {skin }}$ cooling has been associated with the vasoconstriction due to the muscular contraction. This suppression of blood flow potentiates an increase in the probability of musculoskeletal problems.

In this context, the $\Delta T$ calculation between mean $T_{\text {skin }}$ before and after the task, for each ROI, consists of a useful and valid method of analysing the thermal differences along a heterogeneous sample (in this case, participants with different body constitutions).

It is important to emphasise that to the authors' best knowledge, this is the first research attempt that addresses the infrared imaging application to study lifting tasks and with a heterogeneous sample including non-obese and obese individuals.

The outcomes presented in this work constitute an important starting point for future IRT imaging works centred, on this research topic. Similar research should be performed with a larger sample of participants (to improve the statistical power of the conclusions), together with other types of physiological and biomechanical data, and other types of handling tasks.

\section{Acknowledgments}

The authors want to acknowledge the work of the participants, who volunteered to participate in this experimental study.

\section{Disclosure statement}

In accordance with Taylor \& Francis policy and my ethical obligation as a researcher, I am reporting that I have no conflict of interest.

\section{Funding}

This work has been supported by FCT - Fundação para a Ciência e a Tecnologia within the Project Scope: [UID/CEC/00319/2019].

\section{Notes on contributors}

Ana Colim has a Ph.D. in Industrial and Systems Engineering and an MSc in Human Engineering from the University of Minho (Portugal). She is an Invited Professor on Ergonomics and Human Factors at the Department of Production and Systems, School of Engineering at the University of Minho. She currently develops her scientific research at the Algoritmi Centre (University of Minho). Her areas of scientific interest are Biomechanics, Applied Ergonomics, Occupational Safety, and Hygiene.

Pedro Arezes is a Full Professor on Human Factors Engineering at the University of Minho, Portugal, and a visiting scholar at MIT and Harvard University. He coordinates the Ergonomics \& Human Factors research 
group at the Algoritmi Centre (University of Minho). He has been working and publishing in several domains of Occupational Health and Safety, Ph.D. program in Industrial and Systems Engineering.

Paulo Flores holds a Ph.D. degree in Mechanical Engineering from 630 University of Minho (2005). He is currently Full Professor at the Department of Mechanical Engineering and Centre for MicroElecttroMechanical Systems (CMEMS-UMinho) at University of Minho. Paulo Flores is Editor-In-Chief of the journal Mechanism and Machine Theory and Associate Editor of the other several journals. The main research interests of Paulo Flores are the theory of machines and mechanisms, dynamics of multibody systems, biomechanics, medical devices, contact-impact in mechanical systems and higher education.

Ricardo Vardasca holds a Ph.D. degree in Medical Informatics and a BSC (hons) in Information Technology from the University of South Wales (UK)

640 He currently is a Senior researcher at University of Porto, External Professor at the U. Valencia and visiting fellow at U. South Wales. He currently serves as general secretary of the European Association of Thermology. Since 2017 he is an Accredited Senior Imaging Scientist and Fellow of the Royal Photographic Society. He is also a member of the committee ISO/TC121/ SC3-IEC62D/JWG8, Project Team 9 on Screening Thermographs.

Ana Cristina Braga (Chemical Engineer, MSc in Probability and Statistics, Ph.D. in Applied Statistics). Currently, she is Assistant Professor at the Department of Production and Systems, School of Engineering, University of Minho, Portugal. She is responsible for curricular units at first and 2nd cycle of studies in the area of Applied Statistics. She is responsible for Q8 Quantitative and Qualitative Methods in Engineering in Ph.D. programs in Engineering. From 2004 to 2011 was Invited Professor in several Masters of Dental Medicine. She carries out its scientific activity in Applied Statistics at the Algoritmi Centre in the same university. Her research interest is in developing high impact statistical methods and useful, easy-to-use tools for application in bioinformatics, industry, and medicine with a particular focus on genetics and dentistry. Scientific supervisor, in the area of Applied Statistics of $10 \mathrm{Ph} . \mathrm{D}$. projects (7 concluded). One of these projects is in industrial context. She is co-author of more than 75 indexed publications.

\section{ORCID}

Ana Colim (iD http://orcid.org/0000-0003-1138-1534 Pedro Arezes (ID http://orcid.org/0000-0001-9421-9123

Paulo Flores (D) http://orcid.org/0000-0002-7013-4202

Ana Cristina Braga (D) http://orcid.org/0000-0002-1991-9418

\section{References}

Akpinar E, Bashan I, Bozdemir N, Saatci E. 2007. Which is the best anthropometric technique to identify obesity: body mass index, waist circumference or waist-hip ratio? Coll Antropol. 31:387-393.

Ammer K. 2008. Standard procedures for recording and evaluation of thermal images of the human body: the glamorgan protocol. Thermol Int. 18(4):125-144.

Ammer K, Ring EFJ. 2000. The technique of infrared imaging in medicine. Thermol Int. 10(1):7.

Antwi-Afari MF, Li H, Edwards DJ, Pärn EA, Owusu-Manu D, Seo J, Wong AYL. 2018. Identification of potential biomechanical risk factors for low back disorders during repetitive rebar lifting. CIB. 18(2).

Antwi-Afari MF, Li H, Edwards DJ, Pärn EA, Seo J, Wong AYL. 2017. Biomechanical analysis of risk factors for work-related musculoskeletal disorders during repetitive lifting task in construction workers. Automat Constr. 83:41-47.

Arezes PM, Miguel AS, Colim AS. 2011. Manual materials handling: knowledge and practices among Portuguese health and safety practitioners. Work. 39(3):385-395.

Barker L, Hughes L, Babski-Reeves K. 2006. Efficacy of using thermography to assess shoulder loads during overhead intermittent work. Proc Hum Factors Ergon Soc Annu Meet. 50(13):1313-1317.
Beechy L, Galpern J, Petrone A, Krupa Das S. 2012. Assessment tools in obesity - psychological measures, diet, activity, and body composition. Physiol Behav. 107:154-171.

Bernard V, Staffa E, Mornstein V, Bourek A. 2013. Infrared camera assessment of skin surface temperature - effect of emissivity. Phys Med. 29:583-591.

Bertmaring I, Babski-Reeves K, Nussbaum M. 2008. Infrared imaging of the anterior deltoid during overhead static exertions. Ergonomics. 51 (10):1606-1619.

Butler H, Hubley-Kozey C, Kozey J. 2009. Electromyographic assessment of trunk muscle activation amplitudes during a simulated lifting task using pattern recognition techniques. J Electromyogr Kines. 19:e505-e512.

Calin MA, Mologhianu G, Savastru R, Calin MR, Brailescu CM. 2015. A review of the effectiveness of thermal infrared imaging in the diagnosis and monitoring of knee diseases. Infrared Phys Technol. 69:19-25.

Carbonell L, Quesada JIP, Retorta P, Benimeli M, De Anda RMCO, Palmer RS, Peña RJG, Galindo C, Almero LP, Blasco MC, et al. 2018. Thermographic quantitative variables for diabetic foot assessment: preliminary results. Comput Methods Biomech Biomed Eng Imaging Vis. doi:10.1080/ 21681163.2018.1542349

Carmo I, Santos O, Camolas J, Vieira J, Carreira M, Medina L, Reis L, Myatt J, Galvão-Teles A. 2008. National prevalence of obesity - overweight and obesity in Portugal: national prevalence in 2003-2005. Obes Rev. 9(1):11-19.

Casanova OB, Gómez FN, Quesada JIP, De Anda RMCO, Peña RJG, Rey MFM, Almero LP, Palmer RS. 2018. Application of Infrared Thermography as a complementary technique to conventional imaging techniques in paediatrics: case studies. Comput Methods Biomech Biomed Eng Imaging Vis. doi:10.1080/21681163.2018.1542347

Cavuoto L, Nussbaum M. 2013. Obesity-related differences in muscular activity during sustained isometric exertions. Appl Ergon. 44:254-260.

Cavuoto L, Nussbaum M. 2014. The influences of obesity and age on functional performance during intermittent upper extremity tasks. J Occup Environ Hyg. 11(9):583-590.

Colim A, Arezes P, Flores P, Monteiro PRR, Mesquita I, Braga AC. 2019. Obesity effects on muscular activity during lifting and lowering tasks. Int J Occup Saf Ergon. 1-9. doi:10.1080/10803548.2019.1587223

Corbeil P, Plamondon A, Handrigan G, Vall'ee-Marcottea J, Laurendeaua S, Ten Havea J, Manzerollea N. 2019. Biomechanical analysis of manual material handling movement in healthy weight and obese worker. Appl Ergon. 74:124-133.

Deurenberg P, Yap M, van Staveren W. 1998. Body mass index and percent body fat: a meta-analysis among different ethnic groups. Int J Obes. 22:1164-1171.

Dolan P, Kingma I, van Dieen J, Looze M, Toussaint H, Baten C, Adams M. 1999. Dynamic forces acting on the lumbar spine during manual handling: can they be estimated using electromyographic techniques alone? Spine. 24(7):698-703.

Fernández-Cuevas I, Marins J, Lastras J, Carmona P, Cano S, García-Concepción M, Sillero-Quintana M. 2015. Classification of factors influencing the use of Infrared Thermography in humans: a review. Infrared Phys Technol. 71:28-55.

Formenti D, Ludwig N, Trecroci A, Gargano M, Michielon G, Caumo A, Alberyi G. 2016. Dynamics of thermographic skin temperature response during squat exercise at two different speeds. J Therm Biol. 59:58-63.

Fournet D, Ross L, Voelcker T, Redortier B, Havenith G. 2013. Body mapping of thermoregulatory and perceptual responses of males and females running in the cold. J Therm Biol. 38(6):339-344.

Gates D, Succop P, Brehm B, Gillespie G, Sommers B. 2008. Obesity and presenteeism: the impact of body mass index on workplace productivity. JOEM. 50(1):39-45.

Gold J, Cherniack M, Hanlon A, Soller B. 2010. Skin temperature and muscle blood volume changes in the hand after typing. Int J Ind Ergon. 40 (2):161-164.

Govindu N, Babski-Reeves K. 2012. Reliability of thermal readings of the skin surface over anterior deltoid during intermittent, overhead tapping tasks. Int J Ind Ergon. 42:136-142.

Gu JK, Charles LE, Andrew ME, Ma CC, Hartley TA, Violanti JM, Burchfiel CM. 2016. Prevalence of work-site injuries and relationship between obesity and injury among U.S. workers: NHIS 2004-2012. J Saf Res. 58 (2016):21-30. 
Hagberg M, Wegman D. 1987. Prevalence rates and odds ratios of shoulder-neck diseases in different occupational groups. $\mathrm{Br} \mathrm{J}$ Ind Med. 44:602-610.

Horie L, Barbosa-Silva M, Torrinhas R, de Mello M, Cecconello I, Waitzberg D. 2008. New body fat prediction equations for severely obese patients. Clin Nutr. 27:350-356.

Hulens M, Vansant R, Lysens R, Claessens A, Muls E, Brumagne S. 2001. Study of differences in peripheral muscle strength of lean versus obese women: an allometric approach. Int J Obes Relat Metab Disord. 25(5):676-678.

Johnson JM. 1992. Exercise and the cutaneous circulation. Exerc Sport Sci Rev. 20:59-97.

Jones B, Plassmann P. 2002. Digital infrared thermal imaging of human skin. IEEE Eng Med Biol Mag. 21(6):41-48.

Kingma I, van Dieën J. 2004. Lifting over an obstacle: effects of one-handed lifting and hand support on trunk kinematics and low back loading. J Biomech. 37:249-255.

Kurt S, Kisacik B, Kaplan Y, Yildirim B, Etikan I, Karaer H. 2008. Obesity and carpal tunnel syndrome: is there a causal relationship? Eur Neurol. 59 (5):253-257.

Kyle U, Bosaeu I, Lorenzo A, Deurenberg P, Elia M, Gómez J, Heitmann B, Kent-Smith L, Melchior J, Pirlich M, et al. 2004. Bioelectrical impedance analysis-part II: utilization in clinical practice. Clin Nutr. 23:1430-1453.

Lidstone J, Ells L, Finn P, Whittaker V, Wilkinson J, Summerbell C. 2006. Independent associations between weight status and disability in adults: results from the health survey for England. Public Health. 120:412-417.

Lier $\mathrm{H}$, Biringer $\mathrm{E}$, Eriksen $\mathrm{H}$, Tangen T. 2009. Subjective health complaints in a sample with morbid obesity and the complaints' relation with work ability. Eur Psychiatry. 24(S1):750.

Lin T, Verma S, Courtney T. 2013. Does obesity contribute to non-fatal occupational injury? Evidence from the national longitudinal survey of youth. Scand J Work Environ Health. 39(3):268-275.

Ludwig N, Formenti D, Gargano M, Alberti G. 2014. Skin temperature evaluation by Infrared Thermography: comparison of image analysis methods. Infrared Phys Technol. 62:1-6.

Maffiuletti N, Jubeau M, Munzinger U, Bizzini M, Agosti F, De Col A, Lafortuna C, Sartorio A. 2007. Differences in quadríceps muscle strength and fatigue between lean and obese subjects. Eur J Appl Physiol. 101(1):51-59.

Marras W. 2000. Occupational low back disorder causation and control. Ergonomics. 43(7):880-902.

McKean C, Potvin J. 2001. Effects of a simulated industrial bin on lifting and lowering posture and trunk extensor muscle activity. Int J Ind Ergon. 28:1-15.

Merla A, Mattei P, Di Donato L, Romani G. 2010. Thermal imaging of cutaneous temperature modifications in runners during graded exercise. Ann Biomed Eng. 38:158-163.

Meyers B, Keir P. 2003. Trunk muscle response to lifting unbalanced loads with and without knowledge of centre of mass. Clin Biomech. 18:712-720.

805 Mital A, Nicholson A, Ayoub M. 1997. A guide to manual materials handling 2nd ed. London: Taylor \& Francis.

Morris S. 2007. The impact of obesity on employment. Labour Econ. 14:413-433.

Nigatu YT, van de Ven HA, van der Klink JJ, Brouwer S, Reijneveld SA, Bültmann U. 2016. Overweight, obesity and work functioning: the role of working-time arrangements. Appl Ergon. 52:128-134.

Oliveira J, Vardasca R, Pimenta M, Gabriel J, Torres J. 2016. Use of Infrared Thermography for the diagnosis and grading of sprained ankle injuries. Infrared Phys Technol. 76:530-541.

Paniagua L, Lohsoonthorn V, Lertmaharit S, Jiamjarasrangsi W, Williams $M$. 2008. Comparison of waist circumference, body mass index, percent body fat and other measure of adiposity in identifying cardiovascular disease risks among Thai adults. Obes Res Clin Pract. 2:215-223.

Park W, Singh D, Levy M, Jung E. 2009. Obesity effect on perceived postural stress during static posture maintenance tasks. Ergonomics. iFirstarticle. 1-14.

Pereira T, Nogueira-Silva C, Simoes R. 2016. Normal range and lateral symmetry in the skin temperature profile of pregnant women. Infrared Phys Technol. 78:84-91.

Plamondon A, Lariviere C, Denis D, Mecheri H, Nastasia I, IRSST MMH research group. 2017. Difference between male and female workers lifting the same relative load when palletizing boxes. Appl Ergonomics. 60:93-102.

Potvin J, McGill S, Norman R. 1991. Trunk muscle and lumbar ligament contributions to dynamic lifts with varying degrees of trunk flexion. Spine. 10:1099-1107.

Pryce R, Kriellaars D. 2014. Body segment inertial parameters and low back load in individuals with central adiposity. J Biomech. 47(12):3080-3086.

Quesada JIP, Carpes FP, Bini RR, Palmer RS, Pérez-Soriano P, Anda RMCO. 2015. Relationship between skin temperature and muscle activation during incremental cycle exercise. J Therm Biol. 48:28-35.

Ring EFJ. 2006. The historical development of thermometry and the thermal imaging in medicine. J Med Eng Technol. 30(4):192-198.

Rossignoli I, Fernández-Cuevas I, Benito P, Herrero A. 2016. Relationship between shoulder pain and skin temperature measured by Infrared Thermography in wheelchair propulsion test. Infrared Phys Technol. 76:251-258.

Sangachin M, Cavuoto L. 2016. Obesity-related changes in prolongued repetitive lifting performance. Appl Ergon. 56:19-26.

Santos M, Silva L, Júnior J, Lemos T, Matheus J. 2014. Thermographic: a tool of aid in physical therapy diagnosis - literature review. Man Ther Posturol Rehabilit J. 12:364-371.

Saunders M, Lewis P, Thornhill A. 2007. Research methods for business students. 4th ed. Financial Times Prentice-Hall

Savastano D, Gorbach A, Eden H, Brady S, Reynolds J, Yanovski J. 2009. Adiposity and human regional body temperature. Am J Clin Nutr. 90:1124-1131.

Seixas A, Vilas-Boas MC, Carvalho R, Coelho T, Ammer K, Vilas-Boas JP, Mendes J, Cunha JPS, Vardasca R. 2018. Skin temperature of the foot: comparing transthyretin familial amyloid polyneuropathy and diabetic foot patients. Comput Methods Biomech Biomed Eng Imaging Vis doi:10.1080/21681163.2018.1471621

Shariat A, Cardoso JR, Cleland JA, Danaee M, Ansari NN, Kargarfard M, Mohd T, Shamsul B. 2018. Prevalence rate of neck, shoulder and lower back pain in association with age, body mass index and gender among Malaysian office workers. Work. 60(2):191-199.

Shiri R, Solovieva S, Husgafvel-pursiainen K, Telama R, Yang X, Viikari J, Viikari-Juntura E. 2013. The role of obesity and physical activity in non-specific and radiating low back pain: the young finns study. Semin Arthritis Rheum. 42(6):640-650.

Singh D, Park W, Levy M. 2009. Obesity does not reduce maximum acceptable weights of lift. Appl Ergon. 40(1):1-7.

Tanimoto M, Kawano H, Gando Y, Sanada K, Yamamoto K, Ishii N, Tabata I, Miyachi M. 2009. Low-intensity resistance training with slow movement and tonic force generation increases basal limb blood flow. Clin Physiol Funct Imaging. 29(2):128-135.

Torii M, Yamasaki M, Sasaki T, Nakayama H. 1992. Fall in skin temperature of exercising man. Br J Sp Med. 26(1):29-32.

Tsai S, Ashmed F, Wendt J, Bhojani F, Donnelly R. 2008. The impact of obesity on illness absence and productivity in an industrial population of petrochemical workers. AEP. 18(1):8-14.

Umer W, Li H, Szeto GPY, Wong AYL. 2016. Identification of biomechanical risk factors for the development of lower-back disorders during manual rebar tying. J Constr Eng M ASCE. 143(1):04016080.

Vardasca R, Ring F, Plassmann P, Jones C 2008. Thermal monitoring of hand stress during keyboard typing. Proceedings of the 9th International Conference on Quantitative Infrared Thermography. [accessed 2017 Jan 29]. doi:10.21611/qirt.2008.03_16_17

Waters T, Putz-Anderson V, Garg A, Fine L. 1993. Revised NIOSH equation for the design and evaluation of manual lifting tasks. Ergonomics. 36 (7):749-776.

Werner R, Franzblau A, Gell N, Ulin S, Armstrong T. 2005. A longitudinal study of industrial and clerical workers: predictors of upper extremity tendonitis. J Occup Rehabil. 15(1):37-46.

Williams N, Forde M. 2009. Ergonomics and obesity. Appl Ergon. 40:148-149. World Health Organization - WHO. 2016. Obesity and overweight. Geneva (CH): WHO; [accessed 2017 Jan 29]. http://www.who.int/mediacentre/ factsheets/fs311/en/

Yeung S, Genaidy AM, Huston R, Karwowski W. 2002. An expert cognitive approach to evaluate physical effort and injury risk in manual lifting a brief report of a pilot study. Hum Factor Ergon Man. 12(2):227-234. 